\title{
Moringa oleifera na alimentação de bezerros lactentes da raça Pantaneira
}

\author{
"Moringa oleifera" in feeding of suckling calves of the Pantaneira breed
}

\author{
OLIVEIRA, Marcus Vinicius Morais ${ }^{1}$; CHIODI, Mariane da Silva ${ }^{1}$; FERNANDES, \\ Henrique Jorge $^{1}$; LISITA, Frederico Olivieri²; LUZ, Dirce Ferreira ${ }^{3}$; SALLA, Luciane \\ Elisete $^{1^{*}}$
}

\author{
${ }^{1}$ Universidade Estadual de Mato Grosso do Sul, Aquidauana, Mato Grosso do Sul, Brasil. \\ ${ }^{2}$ Embrapa Pantanal, Corumbá, Mato Grosso do Sul, Brasil. \\ ${ }^{3}$ Universidade Federal de Matogrosso do Sul \\ *Endereço para correspondência: lusalla@yahoo.com.br
}

\section{RESUMO}

Objetivou-se avaliar o desempenho de bezerros da raça Pantaneira durante o período de amamentação. Para tanto, foram utilizados 10 bezerros do nascimento aos 84 dias de vida, com peso corpóreo médio de $23,3 \mathrm{Kg}$, e divididos em dois tratamentos: C - animais que receberam concentrado (grupo controle); e CFM - animais que receberam o concentrado e feno de Moringa Oleifera (Moringa oleifera). O desempenho foi avaliado por meio do ganho de peso médio diário; do crescimento corpóreo, via medições do perímetro torácico e da altura de cernelha e de garupa; do consumo de matéria seca expresso em $\mathrm{kg} /$ dia, da porcentagem do peso corpóreo e em função do peso metabólico; dos consumos de proteína bruta e de fibra em detergente neutro; e da conversão alimentar. Adotou-se o delineamento experimental em blocos inteiramente casualizados, com dois tratamentos e cinco repetições, sendo cada unidade experimental representada por um animal. Foram realizadas análises de variância, e teste de Tukey para a comparação de médias, considerando-se um nível de significância de 5\% de probabilidade. Os animais apresentaram um consumo de matéria seca, ganho de peso médio diário, porcentagem de peso corpóreo e de peso metabólico semelhantes; para ambos os tratamentos. Do mesmo modo ocorreu para a conversão alimentar e a proteína bruta, exceto para fibra em detergente neutro onde os animais alimentados com feno apresentaram um maior consumo. O desempenho dos bezerros lactentes Pantaneiros não foi influenciado com a inclusão do feno de moringa.

Palavras-chave: desempenho, índices zootécnicos, pecuária

\section{SUMMARY}

The present study aimed to evaluate the performance of calves of the Pantaneira breed during the breastfeeding period. For this, were used ten calves, from birth to 84 days of life, with a mean body weight of $23.3 \mathrm{Kg}$, divided into two treatments: C - animals receiving concentrate, and $\mathrm{CMH}$ animals receiving concentrate and moringa hay (Moringa oleifera). The performance was evaluated by the average daily weight gain; body growth, via measurements of heart girth and height of the withers and the rump; the dry matter intake, expressed as $\mathrm{kg} /$ day, percentage of body weight and as function of metabolic weight; consumption of crude protein and neutral detergent fiber; and feed conversion. The experimental design was a randomized block with two treatments and five replications, each experimental unit represented by an animal. Were realized analyses of variance and Tukey test considering a significance level of $5 \%$ probability. The animals presented a dry matter intake, average daily weight gain, percentage of body weight and similar metabolic weight; for both treatments. Likewise, it occurred for feed conversion and crude protein, except for neutral detergent fiber where hay fed animals showed higher intake. The performance of the suckling calves was not affected by the inclusion of moringa hay.

Keywords: performance, index zootechnical, livestock 


\section{INTRODUÇÃO}

A produção de ruminantes implica em melhorias nos sistemas de produção, e um dos principais fatores que influencia na sua sustentabilidade é a alimentação. Uma estratégia para elevar a economia da atividade é o manejo alimentar adequado, associado ao uso de sistemas intensivos, que disponibilizam alimentos de bom valor nutritivo e de baixo custo. Portanto, em se tratando de alimentação de bezerros, o desaleitamento precoce tornase uma opção interessante do ponto de vista econômico.

Neste sentido, Gonsalves Neto et al. (2008) mencionaram que o desaleitamento precoce, com controle da quantidade de leite fornecida aos bezerros, aliado a um fornecimento precoce de alimentos sólidos, são práticas eficientes na redução dos custos de produção, resultando em maior quantidade de leite para comercialização.

Diante do exposto surge como alternativa de alimentação dos bezerros lactentes a Moringa oleífera, com resultados positivos demonstrado na produção de leite (ALVES et al., 2015). Trata-se de uma espécie arbórea rústica, originária da Índia, adaptada às condições climáticas dos trópicos, fixadora de nitrogênio e tolerante à seca (SILVA et al., 2011).

É resistente a pragas e atinge o ponto de corte para forragem com seis meses após plantio, apresentando elevada taxa de crescimento e alta capacidade de produção de biomassa comestível, com produção superior a 15 toneladas de matéria seca por hectare por ano (KARADI et al., 2006).

As folhas e caules da moringa apresentam teores de matéria seca de 21,0 e $15,0 \%$; e de proteína bruta de 23,0 e $9,0 \%$, respectivamente; e uma digestibilidade média, para a planta inteira, de 44,0\%. Apresenta ainda atividade antioxidante (LAKO et al., 2007).

Aliado ao fato de novas alternativas alimentares a serem testadas, existe a relevância de o Pantanal SulMatogrossense explorar a criação de bovinos Pantaneiros, que nestes últimos quatro séculos passaram por forte processo de seleção natural, adquiriram maior adaptabilidade às condições climáticas e nutricionais, sendo o bovino mais criado na planície pantaneira até sua progressiva substituição por outras raças, em especial o Nelore (SOUZA et al., 2010). Atualmente essa raça encontra-se em risco de extinção, com cerca de 500 indivíduos puros (JULIANO et al., 2011).

Logo, objetivou-se avaliar o uso do feno de moringa na alimentação de bezerros da raça Pantaneira durante o período de aleitamento.

\section{MATERIAL E MÉTODOS}

O ensaio foi conduzido no Núcleo de Bovinos Pantaneiros de Aquidauana (NUBOPAN), pertencente à Universidade Estadual de Mato Grosso do Sul, em Aquidauana, região do Alto Pantanal Sul-Mato-Grossense.

Foram utilizados 10 bezerros Pantaneiros (Bos taurus taurus) recémnascidos com peso corpóreo médio de $23,3 \mathrm{~kg}$ e distribuídos em dois tratamentos com cinco repetições, sendo cada unidade experimental representada por um animal. Os recém nascidos foram mantidos em bezerreiros individuais e distribuídos nos tratamentos em função do sexo e do peso ao nascimento. Assim, logo após o parto foram realizados os primeiros cuidados como a assepsia do umbigo e o fornecimento do colostro via mamadeira, de modo a assegurar uma 
adequada ingestão de imunoglobulinas. Posteriormente, utilizou-se mamadeira. Foram ofertados diariamente 3 litros de leite recém mungido, divididos em duas refeições (matinal e vespertina) em porções equitativas. Na primeira semana também ministrou-se uma dose intramuscular das vitamina A, D, E e K.

Os tratamentos avaliados foram C animais que receberam concentrado (grupo controle); e CFM - animais que receberam concentrado e feno da moringa (Moringa oleifera). A dieta sólida foi fornecida a partir do $10^{\circ}$ dia de vida, respeitando-se um consumo mínimo de $0,5 \%$ do peso corpóreo, no período da manhã, sendo considerada uma sobra de $10 \%$ na matéria natural, a qual foi diariamente pesada e retirada uma amostra equitativa de cada animal e congelada para posterior análise química. Todos os animais também tiveram água e sombra permanentemente.

A utilização dos animais foi aprovada pela Comissão de ética no uso dos animais/ UEMS em 25 de março de 2013, conforme protocolo registrado $\operatorname{sob~n}^{\circ} 007 / 2013$.
O feno foi confeccionado em dias não sujeitos à chuva, sendo o corte da fração comestível (folhas e caules com menos de $1 \mathrm{~cm}$ de diâmetro) efetuado pela manhã, logo após a evaporação do excesso de orvalho. A retirada dos galhos foi manual e após o corte, a forragem era espalhada sobre uma lona plástica, para iniciar o processo de desidratação. $\mathrm{O}$ material cortado foi revolvido durante o dia e empregado o método de torção de um feixe da forrageira para determinação da umidade residual. Ao atingir o ponto de fenação ( 88 a $92 \%$ de matéria seca), o mesmo foi recolhido e armazenado em local seco.

O concentrado continha, na matéria seca, $54,0 \%$ de grão de milho triturado, $37,5 \%$ de farelo de soja tostado, $7 \%$ de melaço em pó e $1,5 \%$ de sal mineral e foram balanceadas para terem $22 \%$ PB e $80 \%$ NDT, de modo a atenderem a exigência preconizada pelo NRC (2001). Na Tabela 1 pode ser observada a composição bromatológica dos alimentos ofertados, sendo as análises efetuadas segundo os procedimentos descritos por Silva \& Queiroz (2002).

Tabela 1. Composição química ${ }^{1}$ do feno de Moringa Oleifera e do concentrado, expressos em porcentagem na matéria seca

\begin{tabular}{lccccccccc}
\hline Alimento & MS & PB & FDN & FDA & Cel & Hem & Lig & EE & MM \\
\hline Feno & 90,12 & 18,40 & 19,47 & 11,07 & 6,94 & 8,40 & 4,13 & 2,30 & 8,52 \\
Concentrado & 89,47 & 22,15 & 12,81 & 3,04 & 0,00 & 0,00 & 1,04 & 2,41 & 6,98 \\
\hline
\end{tabular}

${ }^{1} \mathrm{MS}=$ matéria seca, $\mathrm{PB}=$ proteína bruta, $\mathrm{FDN}=$ fibra em detergente neutro, FDA = fibra em detergente ácido, $\mathrm{Cel}=$ celulose, $\mathrm{Hem}=$ hemicelulose, $\mathrm{Lig}=$ lignina, $\mathrm{EE}=$ extrato etéreo e $\mathrm{MM}=$ matéria mineral.

A pesagem dos animais foi efetuada em balança mecânica, logo após o nascimento e, posteriormente em intervalos de 21 dias $\left(21,42,63\right.$ e $84^{\circ}$ dia); sempre pela manhã $(5 \mathrm{~h} 00)$, após um jejum de sólidos e líquidos de 12 horas. Logo após a pesagem, foram realizadas as medições das alturas de cernelha e da garupa, e do perímetro torácico, com auxílio de um hipômetro e fita métrica.

Os consumos de matéria seca total (CMST) e matéria seca de nutrientes (CMSNut) foram estimados pela diferença entre a quantidade de alimentos fornecida e quantidade de sobras, através das equações: CMST $(\mathrm{kg} /$ dia) = Matéria seca ofertada $(\mathrm{kg})$ - Matéria seca sobras $(\mathrm{kg})$ e CMSNut $(\%)=($ MS ingerida $\mathrm{x} \%$ 
do Nutriente) - (MS sobras $x \quad \%$ Nutriente).

Amostras de sangue, coletadas na veia caudal 4 horas após a alimentação matinal, foram efetuadas no nascimento $\mathrm{e}$ posteriormente no $14,35,56$ e $77^{\circ}$ dias, sendo as mesmas armazenadas em tubos de vacutainer contendo heparina para impedir a coagulação do sangue, sendo o mesmo enviado ao laboratório para serem realizadas análises dos teores de glicose e $\mathrm{N}$-ureia, utilizando-se kits comerciais da empresa Labtest ${ }^{\circledR}$.

O período experimental foi de 84 dias, representando os animais com um consumo estável de concentrado mínimo de 500 gramas/dia, nesse interim, os animais foram desmamados, porém permaneceram nas instalações por mais 7 dias, com as mesmas dietas antes de serem soltos na pastagem.

O delineamento experimental adotado foi o de blocos (sexo) casualizados com dois tratamentos e cinco repetições, sendo cada unidade experimental representada por um animal. Foram realizadas análises de variância, e teste de Tukey considerando-se um nível de significância de $5 \%$ de probabilidade. Como o sexo não foi estatisticamente significativo, esta variável foi retirada do referido modelo.
Foi utilizado o sistema de análise estatística e genética- SAEG (UFV, 2007).

\section{RESULTADOS E DISCUSSÃO}

Ao avaliar a ingestão das dietas dos bezerros lactentes da raça Pantaneira, pode-se observar que os animais que receberam leite e concentrado apresentaram um consumo de alimentos sólidos, expressos em $\mathrm{kg} / \mathrm{dia}$, porcentagem de peso corpóreo e de peso metabólico, estatisticamente semelhante aos alimentados com leite, concentrado e feno de moringa (Tabela 2). Isso evidencia que nessa fase os alimentos volumosos, como o feno, não possuem uma importância vital no processo de transformação da porção do estômago aglandular, ou seja, no desenvolvimento do rúmen-retículo e omaso, de modo a converter o bezerro em um ruminante funcional. Esse efeito deve-se ao pequeno consumo de feno, com média de 51 gramas/animal/dia e a maior resistência dessa categoria animal em suportar os efeitos deletérios da paraqueratose ruminal, haja vista que a dieta era composta basicamente por concentrado.

Tabela 2. Consumos de matéria seca de concentrado e de feno de moringa, em quilogramas por dia, e consumo de matéria seca total, expresso em $\mathrm{kg} / \mathrm{dia}$, percentagem de peso corpóreo e de peso metabólico; e a conversão alimentar de acordo com os respectivos tratamentos

\begin{tabular}{|c|c|c|c|}
\hline \multirow[b]{2}{*}{ Variáveis } & \multicolumn{2}{|c|}{ Tratamentos $^{1}$} & \multirow[b]{2}{*}{$\mathrm{CV}(\%)$} \\
\hline & Concentrado & $\begin{array}{c}\text { Concentrado mais feno de } \\
\text { moringa }\end{array}$ & \\
\hline Consumo de Concentrado - kg/dia & 0,183 & 0,167 & 20,50 \\
\hline Consumo de Feno- kg/dia & 0,000 & 0,051 & 105,65 \\
\hline \multicolumn{4}{|l|}{ Consumo Total } \\
\hline Quilogramas/dia & 0,183 & 0,218 & 19,40 \\
\hline Percentagem peso corpóreo & 0,492 & 0,607 & 31,73 \\
\hline Peso metabólico & 12,151 & 14,860 & 28,02 \\
\hline Conversão alimentar & 0,633 & 0,752 & 46,84 \\
\hline
\end{tabular}


Segundo Baldwin et al. (2004) a transição para que o bezerro se torne um ruminante, envolve profundas mudanças metabólicas e na capacidade do animal em utilizar os ácidos graxos de cadeia curta, produzidos no rúmen, como fonte de energia primária em substituição à glicose fornecida pelo leite; sendo neste ensaio, este efeito, em especial no que tange os aspectos da formação e crescimento papilar, proporcionado pela fermentação ruminal dos ingredientes do concentrado.

Todavia, é notória a necessidade da inclusão de alimentos volumosos na dieta dos animais no período subsequente à desmama, de modo a evitar os problemas de acidose e laminite, bem como para promover um rápido desenvolvimento do tamanho e da musculatura dos tecidos que formam rúmen-retículo e omaso.

Ausência de efeitos significativos sobre o consumo com a inclusão de feno na dieta de animais lactentes também foram notificados por Oliveira et al. (2015) ao fornecerem a bezerros Girolando, desmamados precocemente aos 60 dias de vida, dietas com concentrado, concentrado mais feno de leucena (Leucaena leucocephala) ou concentrado mais feno de alfafa (Medicago Sativa). Oliveira et al. (2013) ao fornecerem feno de alfafa aos 15,30 e $60^{\circ}$ dia de vida a bezerros Girolando, desaleitados aos 90 dias, também não observaram diferenças estatísticas no consumo dos animais alimentados com concentrado em relação aos que receberam concentrado mais feno, independente da época de início do fornecimento do volumoso.

Em relação à conversão alimentar, também não foi verificado diferenças estatísticas entre os tratamentos $(\mathrm{P}>0,05)$, indicando que o aproveitamento dos nutrientes foi similar (Tabela 2), evidenciado pela elevada qualidade nutricional da moringa. Ressalta-se ainda que com o aumento da idade, elevam-se as necessidades energéticas e proteicas para que o bezerro se desenvolva normalmente e possa transpor o estágio de pré-ruminante em um ruminante funcional (LIMA et al., 2012). Assim, quando são ofertadas quantidades fixas de leite, os bezerros passam a buscar outros alimentos para suprir suas necessidades nutricionais.

O consumo de proteína bruta dos animais que receberam concentrado e feno de moringa foi estatisticamente similar aos animais que receberam somente concentrado (Tabela 3). Já a ingestão de fibra em detergente neutro foi superior para os animais alimentados com feno (Tabela 3), porém, o maior aporte de nutrientes disponibilizados pela forrageira não foi suficiente para promover incrementos significativos no ganho de peso diário e no crescimento corpóreo dos animais (Tabelas 4 e 5).

Segundo Oliveira et al. (2007) o fornecimento de volumosos para bezerros lactentes gera mudanças apreciáveis no desenvolvimento dos estratos epiteliais e do volume do rúmen-retículo; sendo muitas vezes também notificado nos animais que recebem somente concentrado e leite, uma formação anormal das papilas e uma queratinização da mucosa ruminal, com redução na capacidade de absorção dos nutrientes. Todavia, é importante salientar que o uso de feno na dieta de bezerros durante a fase de aleitamento não é um consenso entre os pesquisadores, onde muitas vezes a forragem não melhora o desempenho dos animais, ou ainda interfere negativamente, reduzindo o consumo de concentrado e proporcionando menor taxa de ganho de peso corpóreo (KHAN et al., 2011). Corroborando, Bernardes et al. (2007) afirmaram que o desenvolvimento do epitélio ruminal está diretamente relacionado com a ingestão de alimentos ricos em carboidratos não estruturais, tendo as fontes de alimentos fibrosos pouca contribuição na performance de bezerros lactentes. 
Tabela 3. Consumos de Proteína Bruta (PB) e de Fibra em Detergente Neutro (FDN), na matéria seca, do concentrado, feno e dieta total, em função dos tratamentosConcentrado (C) e Concentrado mais feno de moringa (CFM), com os respectivos Coeficientes de Variação (CV)

\begin{tabular}{|c|c|c|c|}
\hline \multirow{2}{*}{ Variáveis } & \multicolumn{2}{|c|}{ Tratamentos $^{1}$} & \multirow{2}{*}{$\mathrm{CV}(\%)$} \\
\hline & $\mathrm{C}$ & CFM & \\
\hline \multicolumn{4}{|l|}{ Consumo PB } \\
\hline Concentrado - g/dia & 40,53 & 36,99 & 10,74 \\
\hline Feno - g/dia & $0,00^{\mathrm{b}}$ & $3,38^{\mathrm{a}}$ & 111,63 \\
\hline Total - g/dia & 40,53 & 46,37 & 10,43 \\
\hline \multicolumn{4}{|l|}{ Consumo FDN } \\
\hline Concentrado - g/dia & 23,44 & 21,39 & 20,23 \\
\hline Feno - g/dia & $0,00^{\mathrm{b}}$ & $9,93^{\mathrm{a}}$ & 110,04 \\
\hline Total - g/dia & $23,44^{\mathrm{b}}$ & $31,32^{\mathrm{a}}$ & 27,01 \\
\hline
\end{tabular}

${ }^{1}$ Letras diferentes na linha indicam diferenças significativas ao nível de $5 \%$ de probabilidade acordo com o Teste de Tukey.

Tabela 4. Consumo de matéria seca e ganho de peso médio diário, expressos em $\mathrm{kg} / \mathrm{dia}$, para cada intervalo de avaliação, de acordo com os tratamentos: T1Concentrado (C) e T2 - Concentrado mais feno da moringa (CFM)

\begin{tabular}{|c|c|c|c|c|}
\hline \multirow{2}{*}{ Itens } & \multicolumn{4}{|c|}{ Intervalos de Avaliação ${ }^{1}$} \\
\hline & $1-21$ dias & $22-42$ dias & 43-63 dias & 64-84 dias \\
\hline \multicolumn{5}{|c|}{ Consumo de MS } \\
\hline \multicolumn{5}{|l|}{ Dieta } \\
\hline $\mathrm{C}$ & $0,036^{\mathrm{b}}$ & $0,107^{\mathrm{a}}$ & $0,233^{\mathrm{a}}$ & $0,356^{\mathrm{a}}$ \\
\hline CFM & $0,034^{\mathrm{b}}$ & $0,073^{\mathrm{a}}$ & $0,221^{\mathrm{a}}$ & $0,339^{\mathrm{a}}$ \\
\hline CV $(\%)$ & 38,80 & 41,80 & 11,75 & 30,69 \\
\hline \multicolumn{5}{|l|}{ Feno } \\
\hline $\mathrm{C}$ & 0,000 & 0,000 & 0,000 & 0,000 \\
\hline CFM & $0,024^{\mathrm{b}}$ & $0,046^{\mathrm{a}}$ & $0,050^{\mathrm{a}}$ & $0,083^{\mathrm{a}}$ \\
\hline $\mathrm{CV}(\%)$ & 114,14 & 107,54 & 106,56 & 106,99 \\
\hline \multicolumn{5}{|l|}{ Total } \\
\hline $\mathrm{C}$ & $0,036^{\mathrm{a}}$ & $0,107^{\mathrm{a}}$ & $0,233^{\mathrm{a}}$ & $0,356^{\mathrm{a}}$ \\
\hline CFM & $0,058^{\mathrm{b}}$ & $0,120^{\mathrm{a}}$ & $0,271^{\mathrm{a}}$ & $0,422^{\mathrm{a}}$ \\
\hline CV $(\%)$ & 41,66 & 30,17 & 36,27 & 28,68 \\
\hline \multicolumn{5}{|c|}{ Ganho de Peso Médio Diário } \\
\hline $\mathrm{C}$ & 0,295 & 0,296 & 0,310 & 0,253 \\
\hline CFM & 0,244 & 0,318 & 0,250 & 0,346 \\
\hline $\mathrm{CV}(\%)$ & 32,02 & 44,62 & 59,11 & 42,70 \\
\hline
\end{tabular}

${ }^{1}$ Letras diferentes na linha indicam diferenças significativas ao nível de $5 \%$ de probabilidade acordo com o Teste de Tukey. 
Tabela 5. Peso corpóreo inicial e final e ganho de peso médio diário (GMD), em função dos tratamentos, Concentrado (C) e Concentrado mais feno de moringa (CFM)), com os respectivos Coeficientes de Variação (CV)

\begin{tabular}{lccc}
\hline Variáveis & \multicolumn{2}{c}{ Tratamentos } & \multirow{2}{*}{ CV (\%) } \\
\cline { 2 - 3 } \cline { 2 - 2 } Peso Corpóreo - $\mathrm{kg}$ & $\mathrm{RC}$ & $\mathrm{RCFM}$ & \\
Inicial & 25,1 & 23,7 & 13,85 \\
Final & 49,3 & 48,1 & 20,00 \\
GMD - kg & 0,289 & 0,290 & 32,05 \\
\hline
\end{tabular}

${ }^{1}$ Não houve diferenças estatísticas entres os tratamentos de acordo com o Teste de Tukey ao nível de 5\% de probabilidade.

Na Tabela 6 podem ser observadas as mensurações do perímetro torácico e das alturas de cernelha e garupa. Segundo Oliveira et al. (2013) a determinação destes parâmetros é importante, pois permite acompanhar o desenvolvimento esquelético do animal, sendo essencial que a bezerra tenha um crescimento corpóreo adequado, já que o tamanho está diretamente relacionado com problemas de distocía e com a futura produção de leite.

No entanto, não foram observados efeitos significativos do feno de moringa no desenvolvimento corpóreo dos animais, tendo ambas as dietas proporcionado perímetro torácico e crescimentos de cernelha e de garupa, semelhantes. De acordo com Bernardes et al. (2007), a utilização de fontes de fibra, na dieta de bezerros lactentes, continua sendo um assunto controverso e, cada vez mais, um maior número de criadores tem optado por não fornecer volumosos para animais até 60 ou 90 dias de idade, tendo em vista que, o crescimento corpóreo não tem apresentado incrementos significativos com a adição de alimentos fibrosos, na dieta dos bezerros.

Tabela 6. Altura e crescimento da cernelha, da garupa e do perímetro torácico, de acordo com as dietas Concentrado (C) e Concentrado mais Feno de Moringa (CFM)

\begin{tabular}{lccccccccc}
\hline Variáveis $^{1,2}$ & ACI & ACF & CTC & AGI & AGF & CTG & PTI & PTF & CTPT \\
\hline C & 66,7 & 80,7 & 14,0 & 70,9 & 84,3 & 13,4 & 66,7 & 84,6 & 17,9 \\
CFM & 64,8 & 79,6 & 14,8 & 70,3 & 83,6 & 13,3 & 63,0 & 83,5 & 20,5 \\
\hline CV & 8,68 & 4,93 & 36,58 & 6,47 & 5,25 & 37,09 & 5,63 & 6,16 & 26,04 \\
\hline
\end{tabular}

${ }^{1} \mathrm{ACI}=$ altura cernelha inicial; $\mathrm{ACF}=$ altura cernelha final; $\mathrm{CTC}=$ crescimento total cernelha; $\mathrm{AGI}=$ altura garupa inicial; $\mathrm{AGF}=$ altura garupa final; $\mathrm{CTG}=$ crescimento total garupa; $\mathrm{PTI}=$ perímetro torácico inicial; $\mathrm{PTF}=$ perímetro torácico final; $\mathrm{CTPT}=$ crescimento total perímetro torácico.

${ }^{2}$ Não houve diferenças estatísticas entres os tratamentos de acordo com o Teste de Tukey ao nível de 5\% de probabilidade.

Os níveis plasmáticos de glicose e de ureia não foram significativos entre os tratamentos $(\mathrm{P}>0,05)$, com média de 75,04 e $16,79 \mathrm{mg} / \mathrm{dL}$, respectivamente (Tabela 7). Os níveis glicêmicos observados estão entre os valores considera- dos normais para bovinos que podem variar de 45,00 a 75,00 mg/dL (KANE$\mathrm{KO}$ et al., 1997) e de ureia sérica que pode chegar até $27,4 \mathrm{mg} / \mathrm{dL}$ (JENKINS et al., 1982). 
Tabela 7. Níveis plasmáticos de glicose e de ureia, de acordo com os respectivos tratamentos: Concentrado (C) e Concentrado mais Feno de Moringa (CFM)

\begin{tabular}{|c|c|c|c|}
\hline \multirow{2}{*}{ Parâmetros } & \multicolumn{2}{|c|}{ Tratamentos $^{1}$} & \multirow{2}{*}{ CV $(\%)$} \\
\hline & $\mathrm{C}$ & CFM & \\
\hline Glicose $(\mathrm{mg} / \mathrm{dL})$ & 74,41 & 75,67 & 7,72 \\
\hline Ureia $(\mathrm{mg} / \mathrm{dL})$ & 16,13 & 17,46 & 7,58 \\
\hline
\end{tabular}

${ }^{1}$ Letras diferentes na linha indicam diferenças significativas ao nível de $5 \%$ de probabilidade acordo com o Teste de Tukey.

O uso de feno de moringa pode ser utilizado na dieta de bezerros lactentes Pantaneiros, uma vez que, o mesmo não influenciou de forma negativa no desempenho dos animais.

\section{AGRADECIMENTOS}

CAPES, CNPq, FUNDECT, MCTIC, MEC, Governo Federal, Centro de Pesquisa do Pantanal (CPP) e Rede Pró-Centro-Oeste pelo financiamento do projeto e concessão das bolsas de estudo dos discentes.

\section{REFERÊNCIAS}

ALVES, F.V.; BRITO, M.C.B.; JULIANO, L.S.; ABREU, U.J.P.; SOUZA, J.C.; SANTOS, S.A. Fatores que influenciam no desempenho de bezerros pantaneiros criado em pastagem nativa no pantanal. Actas Iberoamericanas de Conservación Animal, v.5, n.3, p.38-43, 2015.

BALDWIN, R.L.; McLEOD K.R.; KLOTZ, J.L.; HEITMANN, R.N. Rumen development, intestinal growth and hepatic metabolism in the pre- and postweaning ruminant. Journal of Dairy Science, v.87, n.5, p.55-65, 2004. (Supplement).
BERNARDES, E.B.; COELHO, S.G.; CARVALHO, A.U.; OLIVEIRA, H.N.; REIS, R.B.; SATURNINO, H.M.; SILVA, C.A.; COSTA, T.C. Efeito da substituição do feno de Tifton 85 pelo caroço de algodão como fonte de fibra na dieta de bezerros. Arquivo Brasileiro de Medicina Veterinária e Zootecnia, v.59, n.4, p.955-964, 2007.

GONSALVES NETO, J.; SILVA, F. F.; BONOMO, P. NASCIMENTO, P. V. N.; FERNANDES, S. A. A.; PEDREIRA, M. S.; VELLOSO, C. M.; TEXEIRA, F. A.; Desempenho de bezerros da raça Holandesa alimentados com concentrado farelado ou peletizado. Revista Brasileira de Saúde e Produção Animal [online], v.9, n.4, p.726-733, 2008.

JENKINS, S.J.; GREEN, S.A.; CLARK, P.A. Clinical chemistry reference values of normal domestic animals in various age groups - AS determined on the ABA100. Cornell Veterinarian, v.72, n.4, p.403-415, 1982.

JULIANO, R.S.; RAMOS, A.F.; SANTOS, S.A.; ABREU, U.G.P. Análise de características reprodutivas indicadoras de puberdade em tourinhos Pantaneiros. Archivos de Zootecnia, v.60, n.231, p.325-3208, 2011.

KANEKO, J.J.; HARVEY, J.W.; BRUSS, M.L. Clinical Biochemistry of

Domestic Animals. 5.ed. San Diego: Academic Press, 1997. 932p. 
KARADI, R.V.; GADGE, N.B.; ALAGAWADI, K.R.; SAVADI, R.V. Effect of Moringa oleifera Lam. rootwood on ethylene glycol induced urolithiasis in rats. Journal of Ethnopharmacology, v.105, n.1-2, p.306-311, 2006.

KHAN, M.A., WEARY, D.M., VON KEYSERLINGK, M.A.G. Hay intake improves performance and rumen development of calves fed higher quantities of milk. Journal of Dairy Science, v.94, n.7, p.3547-3553, 2011.

LAKO, J.; TRENERRY, V. C.; WAHLQVIST, M.; WATTANAPENPAIBOON, N.; SOTHEESWARAN, S.; PREMIER, R. Phytochemical flavonols, carotenoids and the antioxidant properties of a wide selection of Fijian fruit, vegetables and other readily available foods. Food Chemistry, v.101, n.4, p.1727-1741, 2007.

LIMA, P.O.; CÂNDIDO, M.J.D; QUEIROZ, M.G.R.; FERREIRA, J. M.; MODESTO, E. C.; LIMA, R. N.; GOMES, J. M. C.; AQUINO, R. M. S.; Parâmetros séricos de bezerros submetidos a diferentes tipos dietas líquidas. Revista Brasileira de Saúde e Produção Animal [online], v.13, n.2, p.529-540, 2012.

NATIONAL RESEARCH COUNCIL NRC. Nutrient requirements of dairy cattle. 7 th ed. rev. Washington, 2001, $381 \mathrm{p}$.

OLIVEIRA, M.V.M; ABREU, C.; VARGAS JUNIOR, F.M.; FERNANDES, H.J.; SALLA, L.E. Efeito do feno de leguminosa no desempenho de bezerros lactentes.

Revista Ciência Agronômica, v.46, n.3, p.654-660, 2015.
OLIVEIRA, D.P.; OLIVEIRA, M.V.M.; VARGAS JÚNIOR, F.M.; LUZ, D.F.; SIMÕES, A.R.P.; OLIVEIRA, C.A.L.; BRAGA NETTO, A.L.; SILVA, S.C.C. Desempenho de bezerros leiteiros lactentes alimentados com feno. Archivos de Zootecnia, v.62, n.239, p.357-367, 2013.

OLIVEIRA, J.S; ZANINE, A.M.; SANTOS, E.M. Fisiologia, manejo e alimentação de bezerros de corte.

Arquivos de Ciências Veterinária e Zoologia, v.10, n.1, p.39-48, 2007.

SILVA, D.J.; QUEIROZ, A.C. Análises de alimentos: métodos químicos e biológicos. $2^{\mathrm{a}}$ ed. Viçosa, MG: Universidade Federal de Viçosa, 2002, $165 \mathrm{p}$.

SILVA, G.F. da; SANTOS, W. R. dos; MATOS, D.B. de; OLIVEIRA, B.M. de; SANTANA, T.M.; SANTANA, M.M. Estudo do tratamento e clarificação de água com torta de sementes de Moringa oleifera Lam. Revista Brasileira de Produtos Agroindustriais, v.13, n.3, p.295-299, 2011.

SOUZA, J.C.; PEROTTO, D.; ABRAHÃO, J.J.; FREITAS, J.A.; FERRAZ FILHO, P.B.; WEABER, R.L.; LAMBERSON, W.R. Estimativa das distâncias genéticas e componentes principais em bovinos de corte no Brasil. Archivos de Zootecnia, v.59, n.228, p.480-485, 2010.

UNIVERSIDADE FEDERAL DE VIÇOSA- UFV- Sistema de análise estatística e genética. Versão 8.0. Viçosa, MG, 2007.150p.

Data de recebimento: 18/04/2016 Data de aprovação: 31/01/2017 